\title{
Mortality in patients treated with intravitreal bevacizumab for age-related macular degeneration
}

\author{
Joel Hanhart ${ }^{1 *}$, Doron S. Comaneshter ${ }^{2}$, Yossi Freier Dror $^{3}$ and Shlomo Vinker ${ }^{2,4}$
}

\begin{abstract}
Background: The aim of this study is to analyze mortality in patients treated with bevacizumab for wet AMD.

Methods: We conducted a retrospective case-control study between patients who received intravitreal injections of bevacizumab as the sole treatment for exudative AMD between September 2008 and October $2014(n=5385)$ and age and gender matched controls $(n=10,756)$. All individuals included in the study were reviewed for sociodemographic data and comorbidities. Survival analysis was performed using adjusted Cox regression, using relevant adjusted variables.

Results: During follow-up (maximum: 73 months), 1063 (19.7\%) individuals after bevacizumab died compared with 1298 $(12.1 \%)$ in the control group $(P<.001)$. After adjusted Cox survival regression, mortality differed significantly between the groups, Odds ratio $=1.69$, (95\% C.I. 1.54-1.84), $P<.001$.

Conclusions: We found an increased long-term mortality in individuals with wet AMD treated with bevacizumab compared to a same age and gender group without wet AMD.
\end{abstract}

Keywords: Neovascular AMD, Anti-VEGF, Bevacizumab, Safety, Mortality

\section{Background}

Intravitreal anti-vascular endothelial growth factor (antiVEGF) treatment has revolutionized the management of many retinal conditions, including age-related macular degeneration (AMD). Several anti-VEGF agents are used in the treatment of neovascular AMD. Ranibizumab and aflibercept are approved as ophthalmic therapies. Bevacizumab is a full-length humanized monoclonal IgG antibody of $149 \mathrm{kDa}$ that inhibits all VEGF-A isoforms [1]. Approved in 2004 by the FDA, for systemic use in the treatment of certain metastatic cancers, bevacizumab is widely used off-label as intravitreal therapy in neovascular AMD since its efficacy was described more than a decade ago [2].

Reduced systemic VEGF level was demonstrated in patients who received intravitreal anti-VEGF agents, the systemic effect was most obvious with bevacizumab. Intraocular injection of bevacizumab strongly decreases

\footnotetext{
* Correspondence: hanhart@szmc.org.il

${ }^{1}$ Department of Ophthalmology, Shaare Zedek Medical Center, 12 Beyt

Street, 91031 Jerusalem, Israel

Full list of author information is available at the end of the article
}

VEGF serum concentration, to the extent that 1 month after the treatment, VEGF serum level is only $23 \%$ of baseline [3]. Circulating VEGF protects vascular patency and integrity [4].

In prospective studies of bevacizumab treatment for neovascular AMD, mortality was found to be $0.81 \%-10.00 \%$ at 1 year [5-10] and $5.07 \%-5.97 \%$ at 2 years $[11,12]$. A recent meta-analysis of 6 randomized controlled trials reported that approximately $25 \%$ more bevacizumab-treated than ranibizumab-treated patients experienced one or more serious non-ocular adverse events over one and 2 years. Among patients who received bevacizumab, overall mortality was $1.95 \%$ at 1 year (25/1282 patients) and $5.78 \%$ at 2 years (51/882) [13]. Another meta-analysis that comprised 1623 patients reported $1.91 \%$ mortality at 1 year [14]. However, many published studies and meta-analyses were not powered enough to accurately assess the systemic risks of anti-VEGF intravitreal injections [15].

In the public health system in Israel, patients diagnosed with neovascular AMD are offered bevacizumab as a first line agent, in accordance with the efficacy demonstrated by major studies $[5,7-9,11]$. 
We report the mortality of all patients treated during a 6 year period, with intravitreal bevacizumab for neovascular AMD, in the largest health maintenance organization in Israel; and compare it to the mortality of age and gender-matched individuals not-exposed to bevacizumab.

\section{Methods}

Data sources

This retrospective, population-based analysis accessed data from the electronic medical records of all individuals affiliated with Clalit Health Services who received intravitreal injections of bevacizumab for treatment of AMD between September 2008 and October 2014.

Clalit Health Services maintains a chronic disease registry database that includes information collected from a variety of sources: primary care physician reports, medication-use files, hospitalization records, and outpatient clinic records. The methods of registry acquisition and maintenance were described by Rennert and Peterburg [16].

For all individuals included in the analysis, we extracted information from the registry regarding the following conditions, which have been reported to be more prevalent in AMD patients and to be associated with increased mortality [17-19]: smoking, alcohol abuse, ischemic heart disease, cerebrovascular disease, congestive heart failure, liver cancer, obesity, and (unilateral/bilateral) pseudophakia.

The definitions in the Clalit database of alcohol abuse are based on the Diagnostic and Statistical Manual of Mental Disorders, version IV. Cerebrovascular disease was diagnosed following the criteria of the National Institute of Neurological Disorders [20]. The clinical data standards of the American College of Cardiology/American Heart Association Task Force were used to define congestive heart failure and ischemic heart disease [21]. A body mass index of $30 \mathrm{~kg} / \mathrm{m}^{2}$ or higher defined obesity.

Additional information extracted from patients' files included age, gender, marital status, and socioeconomic status.

The date of death was automatically communicated from the Israeli Interior Ministry via the unique national identity number. The cause of death was not recorded.

Ethics approval was obtained from the Ethics Committee of the Clalit Health Services.

\section{Study population}

In the nationwide Clalit Health Services records, we identified patients treated by anti-VEGF for wet AMD, and excluded those for whom there was doubt regarding the indication of the treatment. Forty-seven patients were excluded because it was not possible to eliminate diabetic macular oedema as the indication for injections;
29 since high myopia could not be ruled out as the cause of choroidal neovascularisation; 18 as the reason for treatment may have been a concomitant diagnosis of retinal vein occlusion; in 4 patients, inflammatory conditions were identified as the possible etiology of choroidal neovascularisation. Patients who received other intraocular anti-VEGF agents (pegaptanib, ranibizumab, aflibercept) or systemic anti-VEGF therapy at any time were excluded from the analysis.

For each wet AMD patient treated with bevacizumab in the study group, two individuals were matched in age and gender from the members of Clalit Health Services. A matched control had the same age as the case on the date of first bevacizumab injection. Criteria for this reference group were no recorded exposure to anti-VEGF and continual membership in Clalit Health Services from September 2008 until October 2014, excepting death.

\section{Statistical analysis}

For all ratio variables, means and standard deviations were calculated and baseline differences between the groups evaluated using a t-test. For all nominal variables, absolute frequencies and percentages were calculated and baseline differences between the groups were assessed using a Chi-square test. The socioeconomic ordinal variable baseline differences between the groups were evaluated using the Mann-Whitney test. To compare mortality over time between the groups, survival analysis was performed using adjusted Cox regression. The dependent variable was survival. The time-dependent covariate for the treatment group (bevacizumab) was the interval between the first injection to survival or death; and for the control group, the interval between the start of monitoring (date of first injection in the corresponding bevacizumab treated patient) to survival or death, all truncated at 7 years. Adjusted variables were age, smoking, alcohol abuse, hypertension, diabetes, obesity, congested heart failure, liver cancer, ischemic heart disease, and cerebrovascular accident.

Statistical analyses were conducted using the SPSS statistical software (Version 20). The criterion for accepting the research hypothesis was: Alpha $(\alpha)=.05$ (one-sided). The criterion for negating the preliminary differences between the treatment and the control group was: Alpha $(\alpha)=.05$ (two-sided).

\section{Results}

A total of 5385 individuals met the criteria established for the treatment group; and 10,756 aged and gender matched individuals comprised (the control group).

Sociodemographic and clinical characteristics of the groups are shown in Table 1. Patients in the treatment group were a mean 3.5 months older than controls $(81.2$ vs. 80.9 years). The proportion of males was the same, 
Table 1 Patient characteristics and outcome

\begin{tabular}{|c|c|c|c|}
\hline & $\begin{array}{l}\text { Treated with bevacizumab }(N=5385) \\
N(\%)\end{array}$ & $\begin{array}{l}\text { Not treated with bevacizumab }(N=10,756) \\
N(\%)\end{array}$ & $P$-value \\
\hline Age Start [mean \pm SD] & $81.17 \pm 8.91$ & $80.88 \pm 8.91$ & .051 \\
\hline Male & $2460(45.7)$ & $4916(45.7)$ & .979 \\
\hline Married & $2180(40.5)$ & $4637(43.1)$ & $<.001$ \\
\hline Socioeconomic status $^{a}$ & & & $<.001$ \\
\hline High & $1213(22.6)$ & $2910(27.1)$ & \\
\hline Medium & $2510(46.7)$ & $4620(43.1)$ & \\
\hline Low & $1652(30.7)$ & $3190(29.8)$ & \\
\hline Cataract & $2353(43.7)$ & 3585 (35.9) & $<.001$ \\
\hline Smoking & $1008(18.7)$ & $1555(14.5)$ & $<.001$ \\
\hline Alcohol & $27(.05)$ & $64(.06)$ & .524 \\
\hline Hypertension & $4142(76.9)$ & 7666 (71.3) & $<.001$ \\
\hline Diabetes mellitus & $1821(33.8)$ & 3019 (28.1) & $<.001$ \\
\hline Obesity & $1413(26.2)$ & $2581(24.0)$ & $<.001$ \\
\hline Congestive heart failure & $538(10.0)$ & $893(8.3)$ & $<.001$ \\
\hline Liver cancer & $4(.01)$ & $6(.01)$ & .913 \\
\hline Ischemic heart disease & $2030(37.7)$ & $3434(31.9)$ & $<.001$ \\
\hline Cerebrovascular accident & $857(15.9)$ & $1508(14.0)$ & $<.001$ \\
\hline Mortality & $1063(19.7)$ & $1298(12.1)$ & $<.001$ \\
\hline
\end{tabular}

${ }^{\mathrm{a}}$ Mann-Whitney test

$45.7 \%$ in both groups. A high prevalence of medical comorbidities was found in both groups, though higher in the bevacizumab group.

During follow-up (maximal follow-up of 73 months), 1063 (19.7\%) patients who used bevacizumab died, compared to 1298 (12.1\%) in the control group $(P<.001)$. Cumulative survival was greater in the control group (Table 2, Fig. 1). After adjusted Cox regression, mortality was greater for the treatment group, OR $=1.69$, $(95 \%$ C.I. 1.54-1.84), $P<.001$ (Table 3).

The mean number of injections was significantly lower in patients who died 6.1 (6.43) vs. survived 8.3 (8.82) years, $t(2158)=8.98, P<.001$. Patients died after having being treated during $10.50 \pm 13.57$ months, $18.8 \pm 16.80$ months after the last injection.

\section{Discussion}

We report increased mortality in patients treated with bevacizumab for wet AMD, compared to age and gender matched individuals for whom there was no record of a prescription to any anti-VEGF agent.

Bevacizumab is known to escape the eye, reach the general circulation, and inhibit systemic VEGF-A [3]. VEGF-A is involved in homeostasis and healing in many systems. As an anti-angiogenic agent, bevacizumab may impair the ability of vascular tissues to contribute to healing [4, 22]. Impairment of normal healing rather than direct injury to vital organs seems to explain the long-term adverse effects observed for bevacizumab. However, this is difficult to detect in patients who receive intravenous doses of bevacizumab, due to the reduced survival inherent to the malignant condition being treated; nevertheless, apprehensions have been raised [23].

In the current study, risk factors previously reported to be common to AMD and cardiovascular disease [2426] were found to account in part for the increased mortality of the bevacizumab users. Nevertheless, the increased mortality persisted after adjusting for cardiovascular risk factors. Mortality specifically associated with wet AMD has been attributed to the visual impairment it induces [27]. Anti-VEGF treatments have been demonstrated to restore vision [2, 5, 7-13, 28, 29]. Hence, our results support the contribution of bevacizumab to increased mortality, beyond the condition of wet AMD.

It must be noted that, in our study, cases and controls differ on just about every risk factor for death (Table 1). If inclusion of categorical and quantitative variables did not fully capture the association between the factors and death, then there may be residual confounding. A control group that would circumvent those methodologic issues would consist of patients with wet AMD who did not receive injections. In our era, this population does not exist. Comparing two populations with wet AMD in different periods would introduce other serious bias. 
Table 2 Survival (Life Table)

\begin{tabular}{|c|c|c|c|c|c|c|c|}
\hline $\begin{array}{l}\text { Beva- } \\
\text { cizumab }\end{array}$ & Year & $\begin{array}{l}\text { Entering } \\
\text { Interval }\end{array}$ & $\begin{array}{l}\text { Withdrawing during } \\
\text { Interval }\end{array}$ & $\begin{array}{l}\text { Exposed to } \\
\text { Risk }\end{array}$ & $\begin{array}{l}\text { Terminal } \\
\text { Events }\end{array}$ & $\begin{array}{l}\text { Proportion } \\
\text { Terminating } \\
\end{array}$ & $\begin{array}{l}\text { Cumulative Proportion } \\
\text { Surviving at End of Interval }\end{array}$ \\
\hline \multirow[t]{7}{*}{ No } & $0-1$ & 10,756 & 3050 & 9231 & 517 & .06 & .94 \\
\hline & $1-2$ & 7189 & 2336 & 6021 & 327 & .05 & .89 \\
\hline & $2-3$ & 4526 & 1443 & 3805 & 219 & .06 & .84 \\
\hline & $3-4$ & 2864 & 963 & 2383 & 124 & .05 & .80 \\
\hline & $4-5$ & 1777 & 770 & 1392 & 73 & .05 & .76 \\
\hline & $5-6$ & 934 & 611 & 629 & 32 & .05 & .72 \\
\hline & $6-7$ & 291 & 285 & 149 & 6 & .04 & .69 \\
\hline \multirow[t]{7}{*}{ Yes } & $0-1$ & 5385 & 1527 & 4622 & 470 & .10 & .90 \\
\hline & $1-2$ & 3388 & 1099 & 2839 & 238 & .08 & .82 \\
\hline & $2-3$ & 2051 & 631 & 1736 & 168 & .10 & .74 \\
\hline & $3-4$ & 1252 & 407 & 1049 & 99 & .09 & .67 \\
\hline & $4-5$ & 746 & 313 & 590 & 63 & .11 & .60 \\
\hline & $5-6$ & 370 & 249 & 246 & 21 & .09 & .55 \\
\hline & $6-7$ & 100 & 96 & 52 & 4 & .08 & .51 \\
\hline
\end{tabular}

There would be two major flaws if we wanted to compare AMD patients without neovascularization with patients having the neovascular form. First, information extracted from such electronic medical records lack the precision required to be certain that patients registred as having dry AMD do not suffer from the neovascular form in at least one of their eyes. Then, since wet and dry AMD do not necessarily share the same risk profile [26, 30,31], the risk of confounding by indication would persist.
A limitation of this study is that our database does not differentiate between unilateral and bilateral injections, and provides only limited information on ocular conditions. Visual acuity, for instance, is not recorded. Patients who went on to use other anti-VEGF treatments were excluded from this study. This might introduce a bias into the comparison death rates, as indivuals receiving second line treatments do not necessarily share the same risk profile as people responding to bevacizumab.

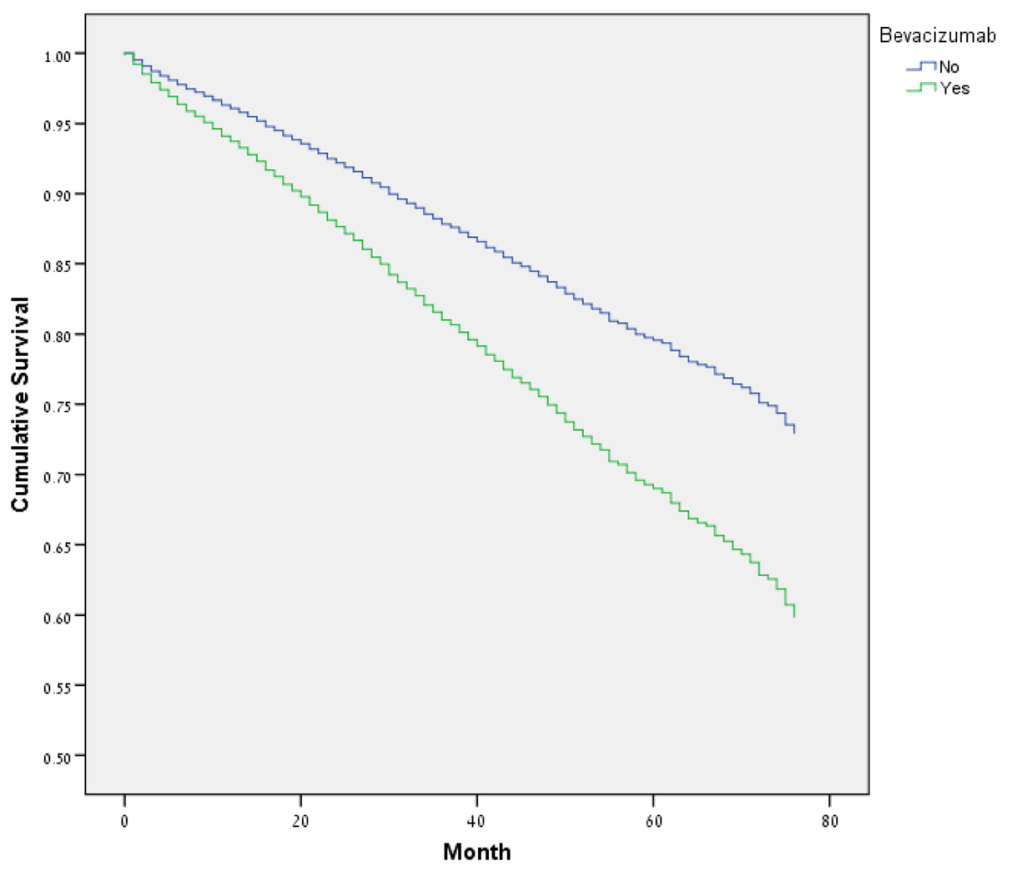

Fig. 1 Cumulative Survival. Cumulative survival is greater in patients who were not exposed to bevacizumab 
Table 3 Mortality (Cox regression)

\begin{tabular}{llllll}
\hline Variables & B & S.E. & Wald $(\mathrm{df}=1)$ & $\mathrm{p}$-value & OR \\
\hline Gender (male) & .053 & .043 & 1.507 & .220 & 1.054 \\
Age start (Year) & .013 & .004 & 12.927 & .000 & 1.013 \\
Socioeconomic (low) & .083 & .057 & 2.093 & .148 & 1.086 \\
Smoking & .162 & .061 & 7.135 & .008 & 1.176 \\
Alcohol & .323 & .240 & 1.809 & .179 & 1.381 \\
Hypertension & .032 & .056 & .322 & .570 & 1.032 \\
Diabetes & .015 & .046 & .106 & .745 & 1.015 \\
Obesity & .071 & .054 & 1.724 & .189 & 1.073 \\
Congestive heart failure & .172 & .055 & 9.779 & .002 & 1.187 \\
Liver cancer & .775 & .516 & 2.255 & .133 & 2.170 \\
Ischemic heart disease & .000 & .046 & .000 & .993 & 1.000 \\
Cerebrovascular accident & .153 & .051 & 9.065 & .003 & 1.166 \\
Bevacizumab use & .527 & .043 & 153.744 & .000 & 1.694 \\
\hline
\end{tabular}

However, to our knowledge, such a difference has never been reported.

Another weakness of our data is that the cause of death is not available. Nevertheless, all-cause mortality has some advantages as a principle end point, given the potential for misclassifying the cause of death [32].

The strength of this study is the inclusion of a large number of patients who received bevacizumab and no other anti-VEGF therapy for wet AMD, with detailed registration of comorbidities and socioeconomic data, which enabled suitable matching and multivariate analysis.

\section{Conclusions}

The findings presented raise questions regarding the use of bevacizumab for wet AMD. Other anti-VEGF intraocular compounds are used as second-line therapy in Israel. Due to the observed delay between the last bevacizumab injection and death, our data do not enable valid assessment of the effects of ranibizumab and aflibercept on mortality. Additional data is needed to corroborate our worrying observation that bevacizumab intraocular injections may be associated with increased mortality. If confounding by indication could be ruled out but economic reasons precluded immediate interruption of bevacizumab therapy for wet AMD, it would be crucial to define groups of higher and lower risk, to enable physicians and patients to discuss the systemic impact of ocular therapy and adequately balance expected gains and risks.

\section{Abbreviations}

AMD: Age-related macular degeneration; FDA: Food and drug administration; VEGF: vascular endothelial growth factor

Acknowledgements

Cindy Cohen provided editing services.
Funding

None.

\section{Availability of data and materials}

The data that support the findings of this study are available from Kupat Cholim Clalit but restrictions apply to the availability of these data, which were used under license for the current study, and so are not publicly available. Data are however available from the authors upon reasonable request and with permission of Kupat Cholim Clalit.

\section{Authors' contributions}

DSC was involved in the acquisition and analysis of the data, YFD in statistical analysis of the data, SV in designing the study and revising the manuscript. JH designed the study, overviewed statistical analysis and drafted the manuscript. All authors made substantial contributions to this study and gave final approval for its submission. All authors read and approved final manuscript.

Ethics approval and consent to participate

Ethics approval was obtained from the Ethics Committee of the Clalit Health Services.

Consent for publication

Not applicable.

\section{Competing interests}

No relevant disclosures for for Doron S Comaneshter, Yossi Freier Dror and Shlomo Vinker. Joel Hanhart has given lectures on diabetic macular edema for Novartis.

\section{Publisher's Note}

Springer Nature remains neutral with regard to jurisdictional claims in published maps and institutional affiliations.

\section{Author details}

${ }^{1}$ Department of Ophthalmology, Shaare Zedek Medical Center, 12 Beyt Street, 91031 Jerusalem, Israel. ${ }^{2}$ Central Headquarters, Clalit Health Services, Tel Aviv, Israel. ${ }^{3}$ Mashav Applied Research, Jerusalem, Israel. ${ }^{4}$ Sackler School of Medicine, Tel Aviv University, Ramat Aviv, Tel Aviv, Israel.

Received: 13 February 2017 Accepted: 3 October 2017

Published online: 10 October 2017

\section{References}

1. Amadio M, Govoni S, Pascale A. Targeting VEGF in eye neovascularization: What's new?: a comprehensive review on current therapies and oligonucleotide-based interventions under development. Pharmacol Res. 2015:103:253-69.

2. Michels S, Rosenfeld PJ, Puliafito CA, Marcus EN, Venkatraman AS. Systemic bevacizumab (Avastin) therapy for neovascular age-related macular degeneration twelve-week results of an uncontrolled open-label clinical study. Ophthalmology. 2005;112(6):1035-47.

3. Matsuyama K, Ogata N, Matsuoka M, Wada M, Takahashi K, Nishimura T. Plasma levels of vascular endothelial growth factor and pigment epithelium-derived factor before and after intravitreal injection of bevacizumab. Br J Ophthalmol. 2010;94(9):1215-8.

4. Tunon J, Ruiz-Moreno JM, Martin-Ventura JL, Blanco-Colio LM, Lorenzo O, Egido J. Cardiovascular risk and antiangiogenic therapy for age-related macular degeneration. Surv Ophthalmol. 2009:54(3):339-48.

5. Berg K, Pedersen TR, Sandvik L, Bragadottir R. Comparison of ranibizumab and bevacizumab for neovascular age-related macular degeneration according to LUCAS treat-and-extend protocol. Ophthalmology. 2015;122(1): $146-52$.

6. Chakravarthy U, Harding SP, Rogers CA, Downes SM, Lotery AJ, Wordsworth $S$, Reeves BC. Ranibizumab versus bevacizumab to treat neovascular agerelated macular degeneration: one-year findings from the IVAN randomized trial. Ophthalmology. 2012;119(7):1399-411.

7. Kodjikian L, Souied EH, Mimoun G, Mauget-Faysse M, Behar-Cohen F Decullier E, Huot L, Aulagner G. Ranibizumab versus Bevacizumab for Neovascular age-related macular degeneration: results from the GEFAL noninferiority randomized trial. Ophthalmology. 2013;120(11):2300-9. 
8. Krebs I, Schmetterer L, Boltz A, Told R, Vecsei-Marlovits V, Egger S, Schonherr U, Haas A, Ansari-Shahrezaei S, Binder S. A randomised doublemasked trial comparing the visual outcome after treatment with ranibizumab or bevacizumab in patients with neovascular age-related macular degeneration. Br J Ophthalmol. 2013;97(3):266-71.

9. Martin DF, Maguire MG, Ying GS, Grunwald JE, Fine SL, Jaffe GJ. Ranibizumab and bevacizumab for neovascular age-related macular degeneration. N Engl J Med. 2011;364(20):1897-908.

10. Subramanian ML, Abedi G, Ness S, Ahmed E, Fenberg M, Daly MK, Houranieh A, Feinberg EB. Bevacizumab vs ranibizumab for age-related macular degeneration: 1-year outcomes of a prospective, double-masked randomised clinical trial. Eye (London, England). 2010;24(11):1708-15.

11. Chakravarthy U, Harding SP, Rogers CA, Downes SM, Lotery AJ, Culliford LA, Reeves BC. Alternative treatments to inhibit VEGF in age-related choroidal neovascularisation: 2-year findings of the IVAN randomised controlled trial. Lancet (London, England). 2013;382(9900):1258-67.

12. Martin DF, Maguire MG, Fine SL, Ying GS, Jaffe GJ, Grunwald JE, Toth C, Redford M, Ferris FL 3rd. Ranibizumab and bevacizumab for treatment of neovascular age-related macular degeneration: two-year results. Ophthalmology. 2012;119(7):1388-98.

13. Solomon SD, Lindsley KB, Krzystolik MG, Vedula SS, Hawkins BS. Intravitreal Bevacizumab versus Ranibizumab for treatment of Neovascular age-related macular degeneration: findings from a Cochrane systematic review. Ophthalmology. 2016;123(1):70-77.e71.

14. Moja L, Lucenteforte E, Kwag KH, Bertele V, Campomori A, Chakravarthy U, D'Amico R, Dickersin K, Kodjikian L, Lindsley K, et al. Systemic safety of bevacizumab versus ranibizumab for neovascular age-related macular degeneration. Cochrane Database Syst. Rev. 2014;9:Cd011230.

15. Thulliez M, Angoulvant D, Le Lez ML, Jonville-Bera AP, Pisella PJ, Gueyffier F, Bejan-Angoulvant T. Cardiovascular events and bleeding risk associated with intravitreal antivascular endothelial growth factor monoclonal antibodies: systematic review and meta-analysis. JAMA Ophthalmol. 2014;132(11):1317-26.

16. Rennert G, Peterburg Y. Prevalence of selected chronic diseases in Israel. Isr Med Assoc J. 2001;3(6):404-8.

17. Ikram MK, Mitchell P, Klein R, Sharrett AR, Couper DJ, Wong TY. Age-related macular degeneration and long-term risk of stroke subtypes. Stroke. 2012; 43(6):1681-3.

18. Klein R, Peto T, Bird A, Vannewkirk MR. The epidemiology of age-related macular degeneration. Am J Ophthalmol. 2004;137(3):486-95.

19. Boberg-Ans G, Henning V, Villumsen J, la Cour M. Longterm incidence of rhegmatogenous retinal detachment and survival in a defined population undergoing standardized phacoemulsification surgery. Acta Ophthalmol Scand. 2006;84(5):613-8.

20. Grinnon ST, Miller K, Marler JR, Lu Y, Stout A, Odenkirchen J, Kunitz S. National Institute of Neurological Disorders and Stroke common data element project - approach and methods. Clinical Trials (London, England). 2012:9(3):322-9.

21. Hicks KA, Tcheng JE, Bozkurt B, Chaitman BR, Cutlip DE, Farb A, Fonarow GC, Jacobs JP, Jaff MR, Lichtman JH, et al. 2014 ACC/AHA key data elements and definitions for cardiovascular endpoint events in clinical trials: a report of the American College of Cardiology/American Heart Association task force on clinical data standards (writing committee to develop cardiovascular endpoints data standards). Circulation. 2015;132(4):302-61.

22. Lim LS, Cheung CM, Mitchell P, Wong TY. Emerging evidence concerning systemic safety of anti-VEGF agents-should ophthalmologists be concerned? Am J Ophthalmol. 2011;152(3):329-31.

23. Richards L. Targeted therapies: disappointing outcomes for anti-VEGF therapy. Nat Rev Clin Oncol. 2011;8(4):194

24. Fisher DE, Jonasson F, Eiriksdottir G, Sigurdsson S, Klein R, Launer $L$, Gudnason V, Cotch MF. Age-related macular degeneration and mortality in community-dwelling elders: the age, gene/environment susceptibility Reykjavik study. Ophthalmology. 2015;122(2):382-90.

25. Klein R, Klein BE, Knudtson MD, Meuer SM, Swift M, Gangnon RE. Fifteenyear cumulative incidence of age-related macular degeneration: the beaver dam eye study. Ophthalmology. 2007;114(2):253-62.

26. Clemons TE, Kurinij N, Sperduto RD. Associations of mortality with ocular disorders and an intervention of high-dose antioxidants and zinc in the age-related eye disease study: AREDS report no. 13. Arch. Ophthalmol. (Chicago, III : 1960). 2004;122(5):716-26.
27. Bandello F, Lafuma A, Berdeaux G. Public health impact of Neovascular agerelated macular degeneration treatments extrapolated from visual acuity. Invest Ophthalmol Vis Sci. 2007;48(1):96-103.

28. Arevalo JF, Lasave AF, Wu L, Acon D, Berrocal MH, Diaz-Llopis M, GallegoPinazo R, Serrano MA, Alezzandrini AA, Rojas S, et al. INTRAVITREAL BEVACIZUMAB FOR CHOROIDAL NEOVASCULARIZATION IN AGE-RELATED MACULAR DEGENERATION: 5-year results of the pan-American collaborative retina study group. Retina (Philadelphia, Pa). 2016;36(5):859-867.

29. Avery RL, Pieramici DJ, Rabena MD, Castellarin AA, Nasir MA, Giust MJ. Intravitreal bevacizumab (Avastin) for neovascular age-related macular degeneration. Ophthalmology. 2006;113(3):363-372.e365.

30. Pedula KL, Coleman AL, Yu F, Cauley JA, Ensrud KE, Hochberg MC, Fink HA, Hillier TA. Age-related macular degeneration and mortality in older women: the study of osteoporotic fractures. J Am Geriatr Soc. 2015;63(5):910-7.

31. Buch $H$, Vinding $T$, la Cour M, Jensen GB, Prause JU, Nielsen NV. Age-related maculopathy: a risk indicator for poorer survival in women: the Copenhagen City eye study. Ophthalmology. 2005;112(2):305-12.

32. Gottlieb SS. Dead is dead-artificial definitions are no substitute. Lancet (London, England). 1997:349(9053):662-3.

\section{Submit your next manuscript to BioMed Central and we will help you at every step:}

- We accept pre-submission inquiries

- Our selector tool helps you to find the most relevant journal

- We provide round the clock customer support

- Convenient online submission

- Thorough peer review

- Inclusion in PubMed and all major indexing services

- Maximum visibility for your research

Submit your manuscript at www.biomedcentral.com/submit
) Biomed Central 